Comparative Philosophy Volume 9, No. 1 (2018): 32-46

Open Access / ISSN 2151-6014

www.comparativephilosophy.org

\title{
ZHUANG ZI AND THE EDUCATION OF THE EMOTIONS
}

\author{
JEFFREY MORGAN
}

\begin{abstract}
This paper examines and defends a conception of the education of emotions found in the Zhuang-Zi. I begin by exploring four principal features of Zhuang Zi's philosophy as it relates to the emotions: his epistemological perspectivism, his view of the self, his ethics of wandering and natural spontaneity, and his playful non-seriousness. Together these four features allow us to discern a general orientation to the education of the emotions, including a normative account of a good emotional life as well some suggestions for a pedagogy for the development of such a life.
\end{abstract}

Keywords: Zhuang Zi, education of the emotions, perspectivism, spontaneity, wu-wei, passivity

The Zhuang- $Z i^{1}$ is a beautiful text, but its philosophical positions and arguments are challenging. Kupperman (2001) sees the work as "the philosophical counterpart to fireworks. Brightly colored lines of thought go off in many directions" $(2001,127)$. One can read the Zhuang-Zi as a kind of "gadfly" to established norms and prevailing hubris with respect to these norms. Nevertheless, I will argue that the text reveals an attractive ideal of the worthwhile life. This ideal has implications for how we ought to conceive of the education of the emotions.

I defend a vision of the emotions, and specifically of the education of the emotions, implicit in the Zhuang-Zi. Now, we must recognize that the text demands interpretation, as systematic argument is very much at odds with the overall sprit of the text. Furthermore, definitive prescriptions for how to respond to specific scenarios or issues are not to be found. Still, while it might be wrong to identify with certainty any single thesis that can be inferred from the text, it is possible to discern a "picture" of what emotional life can and should become. The ideal is one of calm emotions that represent a kind of selfless wandering and responsive, natural, spontaneity. I will say

MORGAN, Jeffrey: Associate Professor of philosophy, University of the Fraser Valley, British Columbia, Canada. Email: Jeffrey.Morgan@ufv.ca

\footnotetext{
${ }^{1}$ Sometimes the earlier Wade-Giles Romanization Chuang Tzu is used, as in Hinton (1998). I use the italicized term Zhuang-Zi to refer to the text, but non-italicized 'Zhuang Zi' refers to Zhuang Zi the man.
} 
more about this vision below.

My interest is in a person's emotional life, broadly conceived. I conceive of emotions as a group of mental states that typically include four dimensions ${ }^{2}$. First, emotions are intentional states that imply appraisal of a situation. So, fear implies appraisal of the bear running toward me as dangerous; guilt implies appraisal of one's actions as falling below a moral standard which one ought to have met; anger implies the appraisal of one as having been wrongly treated by another. Second, emotions are states in which one is passive with respect to one's situation. By "passive" I mean that emotions are reactive rather than active states. An active intentional state is one that implies the affirmation of the subject. Belief is an active state: it would make no sense to say that I believe P unless I think that P is an appropriate object of belief (i.e., that $\mathrm{P}$ is likely a true proposition). Intention and expectation are also active states. However, emotional states can persist even if one thinks that the implicit appraisals are defective: I can fear objects that I believe are not dangerous (clowns), and I can love people who I conceive as unlovable. It is the passivity of emotions that clouds the ascription of responsibility for one's emotional states. I am responsible for my beliefs, but my emotions might well be experienced as having happened to me. (Nevertheless, we can still be responsible for our emotions, but the responsibility is deeper - as a rational adult, I am at least partly responsible for the background knowledge and inclinations that give rise to my emotions, even if I do not directly choose my emotions.) Third, typically emotions contain a "feeling" element to them; they are passions. It is partly by reference to the intensity of feeling that we identify the intensity of emotion. The feelings are often physical but Michael Stocker (1983) recognizes a kind of "psychic" feeling that may not amount to observable bodily changes. Fourth, emotions typically also have a conative dimension-one is motivated to act in a characteristic way due to one's emotions. In anger, I might feel a desire to hit, but in shame I might want to hide my face; in grief I might cry, but in joy I might dance.

We do not literally educate the emotions, any more than we educate beliefs or intentions. Rather, we educate people. Further, when we say that someone has been educated, we imply that she has been changed, through learning, for the better ${ }^{3}$. Put differently, any theory of the education of the emotions must include both a normative component explicating what a person's emotional life should be, as well as a pedagogical component explicating how we attain (or at least approach) an ideal emotional life. The normative condition is purely formal here: I am not at this point

\footnotetext{
${ }^{2}$ Obviously, this account is brief, but is merely intended to demarcate the broad outlines of my subject here. It is drawn from my Ph.D. thesis, but discussed in (Morgan 1994).

${ }^{3}$ I argue for this claim in more detail in (Morgan 2015). I do not offer a thorough defense of it here, but the obvious source is the work of R.S. Peters (1966b), though he employs the stronger condition of "knowledge," rather than simply "learning." (Peters made very important contributions to early analytic study of the emotions, as well as of the education of the emotions (1972).) However, his conception of education focuses on the acquisition of propositional knowledge (learning that P), putting rather less emphasis on other forms of learning, such as learning how to, learning to, or learning to be. The latter two categories-learning habits and virtues respectively - cannot easily be characterized in terms of knowledge acquisition.
} 
saying anything substantive regarding what ought to be valorized. Further, educational achievements must be attained through learning, as opposed to through medication or surgery. We would not refer to a person who had attained a better emotional life through pharmaceuticals as having been thereby educated. From the standpoint of the educator, education demands providing learning experiences that lead to the worthwhile transformation of the student. Consequently, if the idea of educating the emotions is meaningful, then it must be possible to provide learning experiences that transform the student's emotional life.

The above argument, based primarily on ordinary language analysis, might be buttressed by noting that education involves interference in the lives of other people - typically children - and that this interference demands moral defense, as a necessary (but not sufficient) condition of legitimate interference in the lives of children is the reasonable expectation that the interference will be in their interest.

The normative dimension of the education of the emotions is logically prior to the pedagogical: the pedagogical component supplies a means for achieving the normative ideals. This means that we must explicate the normative goals of education of the emotions in order to advance a pedagogical program for achieving those goals. I take it that this is relatively uncontroversial: we must know where we are headed before we set out on a journey to get there. The one caveat arises from the observation that if some transformation, $\mathrm{T}$, cannot be attained through any program of learning, then $\mathrm{T}$ cannot constitute a genuine normative ideal of the education of the emotions.

One further point concerning my use of the term 'education': In ordinary language, we sometimes use 'education' to refer to the institution of the school. We might even think of an educated person as a schooled or credentialed person. I am not using the term in that way here. In this paper, I primarily think of education as something we get from a good schooling, but which could be achieved in other ways. It is possible, on my view, that we could become educated through other institutions (family, media or friendship groups), or even that the school does such a poor job of schooling that we might want to reject schools in order to better educate the young. Still, as it is, schools are central vehicles for the education of young people, and I will make a few brief remarks about schooling for the emotions.

Before beginning my interpretation of the Zhuang-Zi, I want to make a brief note on the text and my approach to it. Zhuang Zi (ca. 369-286 B.C.E.) lived in the Warring States Period (ca. 475-221 B.C.E.) (Ziporyn 2009) ${ }^{4}$. The text bearing his name is the subject of ongoing debate amongst Chinese philosophers, but there is widespread agreement that the first seven chapters, the "Inner Chapters," are most reliably attributed to Zhuang Zi himself. Even here, however, there are parts - such as a paragraph in the fifth chapter describing "a Daoist sage as a ruler who employs penalties, rites, wisdom, and virtue" (Watson 2003, Chapter 5, Note 6) -that seem inconsistent with the general thrust of the text. I focus primarily on the seven Inner

\footnotetext{
${ }^{4}$ Kirkland (2004) argues that there is no reliable evidence that Zhuang Zi ever existed.
} 
Chapters in this paper. I work entirely from translation, drawing on Watson's (2003), along with Ziporyn's (2009) and Hinton's (1998) translations.

\section{ZHUANG-ZI'S APPROACH TO THE EMOTIONS}

The Zhuang-Zi provides insights on both components of the education of the emotions. The normative component is addressed in a reorientation to life focused on selfless wandering and responsive spontaneity. I will say more about this ideal below but I would like to begin by considering its underlying rationale in the Zhuang-Zi. I structure my remarks in four subsections: (a) Zhuang Zi's stance of epistemological perspectivism; (b) its emphasis on the emptiness of the self; (c), the ethic of responsive spontaneity and its relationship with a good emotional life; and (d) the non-seriousness implicit in the Zhuang-Zi's approach to life.

(a) The perspectivism of the Zhuang- $Z i$ is apparent from the opening chapter, with its description of a fish called 'Kun' that is thousands of $l i$ long, which changes into a bird called 'Peng' whose back is thousands of $l i$ across. Peng flies ninety thousand miles to the southern darkness. A cicada and a dove laugh at this story, "saying, 'When we make an effort and fly up, we can get as far as the elm or the sapanwood tree, but sometimes we don't make it and just fall down on the ground. Now how is anyone going to go ninety thousand $l i$ to the south!"' (Watson, Ch. 1). In response, Zhuang-Zi comments "What do these two creatures understand? Little understanding cannot come up to great understanding; the short-lived cannot come up the longlived" (Watson, Ch. 1).

The cicada and the dove see the world from their own perspectives, and cannot therefore be expected to understand the world from a broader (greater) perspective. Like the cicada and the dove, we too must be careful not to apply our own categories to what we cannot understand:

Therefore a man who has wisdom enough to fill one office effectively, good conduct enough to impress one community, virtue enough to please one ruler, or talent enough to be called into service in one state, has the same kind of self-pride as these little creatures. Song Rongzi [an important Daoist sage] would certainly burst out laughing at such a man. (Watson, Ch. 1)

This perspectivism - the tendency to interpret the world from their own viewpointsis the condition of ordinary folk who fail to understand the force and limitations of linguistic distinctions:

Words are not just wind. Words have something to say. But if what they say is not fixed, then do they really say something? Or do they say nothing? People suppose that words are different from the peeps of baby birds, but is there any difference, or isn't there? What does the Way rely upon, that we have true and false? What do words rely upon, that we have right and wrong? How can way go away and not exist? How can words exist and not be acceptable? (Watson, Ch. 2) 
This suggests a subtle form of linguistic relativity mitigated by awareness of a deeper reality (the Dao (道)) that cannot be adequately expressed with words and conceptual distinctions. The sage, however, is capable of getting beyond ordinary distinctions:

He too recognizes a 'this,' but a 'this' which is also a 'that,' a 'that' which is also 'this.' His 'that' has a both a right and a wrong in it; his 'this' too has both a right and a wrong in it. So, in fact, does he still have a 'this' and a 'that'? Or does he no longer have a 'this' and a 'that'? (Watson, Ch. 2)

Further,

The Great Way is not named; Great Discriminations are not spoken; Great Benevolence is not benevolent; Great Modesty is not humble; Great Daring does not attack. If the Way is made clear, it is not the Way. If discriminations are put into words, they do not suffice. (Watson, Ch. 2)

It is clear that the relativism I ascribe to Zhuang $\mathrm{Zi}$ does not amount to subjective relativism, in the sense that "anything goes," as Mou (2008) points out. Mou sees Zhuang $\mathrm{Zi}$ as presenting a version of objective perspectivism inasmuch as it allows for multiple perspectives, with the provision that each perspective "points to some aspect that is really or objectively possessed by the object of study" (p. 415). Mou further points out that Zhuang $\mathrm{Zi}$ "encourages us to look at things from a higher point of view which transcends various finite points of view" (p. 416). If Mou is correct, then (a) we can reject some perspectives as downright wrong, while (b) accepting that others are partly correct. Where we encounter competing but partly correct perspectives, we need to move to a higher perspective that "transcends" the other views. The higher perspective allows the lower perspectives to be seen as opposing but complementary to each other, balanced in the ultimate Dao as a complementarity of opposites (see Beng 2013). Mou argues that such a "transcendental perspective" accords with Zhuang Zi's principal epistemological stance. It is important to keep in mind that this limited relativism maintains the idea of a reality that ultimately grounds our diverse but legitimate perspectives. It still allows us to be realist about the Dao, but perspectivist in our ordinary epistemology. ${ }^{5}$

In the above passages there is a delightful, if confounding, playfulness that expresses the challenge of trying to say the ineffable. Zhuang $\mathrm{Zi}$ is aware of the paradox that his project entails, reflecting a sophisticated understanding of language as both essential to, and a limit of, understanding the world. It is possible that this is a skeptical thesis ${ }^{6}$, but I read the text in the context of a response to the dominant Confucian and Mohist traditions of Warring States China. Both the Confucians and

\footnotetext{
${ }^{5}$ Interestingly, in a comment on Mou's thesis, Searle (2008) denies that it is possible to "have representations without aspectuality, (p. 431). I think that Mou is correct about Zhuang Zi's position, but regarding whether it can answer Searle's objection I reserve judgment.

${ }^{6}$ Raphals (1996) is a very helpful examination of the forms of skepticism in the Zhuang-Zi; she classifies Zhuang Zi's skepticism as a matter of method, rather than of doctrine or recommendation. More recently, Chung (2017) subtly and plausibly interprets the Zhuang-Zi's skepticism in fictionalist terms.
} 
the Mohists are confident in their epistemological and moral claims, and the Zhuang$Z i$ can be read as a biting critical response to what it conceives as hubris. In any case, Zhuang- $\mathrm{Zi}$ is reticent to ascribe categories to experience that have any legitimacy beyond our language, and this perspectivism extends to his views on the self.

(b) The frst chapter of the Zhuang-Zi, "Free and Easy Wandering," says "therefore, I say, the Perfect Man has no self; the Holy Man has no merit; the Sage has no fame" (Watson, Ch. 1); Watson clarifies in a footnote that the Perfect Man, Holy Man and Sage refer to a single individual, not three). Hinton's translation reads, "the realized remain selfless. The sacred remain meritless. The enlightened remain nameless" $(1998,7)$. Ziporyn expresses this as: "the Consummate person has no fixed identity, the Spirit Man has no particular merit, the Sage has no one name" (2009. 6). The ideas of "no self," "selfless," and "no fixed identity" are difficult. Part of the problem is that contemporary conceptions of self are so closely intertwined with Cartesian and post-Cartesian metaphysics that it is difficult to translate this passage without distorting Zhuang Zi's underlying position. This is argued well by Jochim $(1998))^{7}$. I do not read the text as making an anti-Cartesian claim, but rather as making the softer claim that one ought not to focus too greatly on one's own selfimage or identity. Perhaps the Ziporyn translation gets us closer to what is really going on here. The problem is the tendency to definitively fix the self, to use our categories to say "this is me, this is who I am," and thus become closed to change. Zhuang $\mathrm{Zi}$ is clearly opposed to such strong reification of the self.

The admonition not to embrace a strongly-fixed identity is developed further in Chapter 4 of the Zhuang-Zi, where there is an interchange between Confucius and Yen Hui, one of Confucius' favorite students ${ }^{8}$. Yen Hui is asking for permission to assist the ruler of Wei. Confucius prompts Yen Hui to reflect on his goals and the likelihood of success, eventually advising him to practice "fasting of the mind:"

Confucius said, 'Make your will one! Don't listen with your ears, listen with your mind. No don't listen with your mind, but listen with your spirit. Listening stops with the ears, the mind stops with recognition, but spirit is empty and waits on all things. The Way gathers in emptiness alone. Emptiness is the fasting of the mind.' (Watson, Ch. 4)

Yen Hui responds:

Before I heard this, I was certain that I was Hui. But now I have heard it, there is no more Hui. Can this be called emptiness? (Watson, Ch. 4)

Fasting of the mind is an extremely important idea in the Zhuang-Zi. The mind makes distinctions - the Hinton translation reads "mind is limited to tallying things up" (1998, 51)-which express our own selves as much as they represent the world. Zhuang $\mathrm{Zi}$ is advising us to empty ourselves of this faculty.

\footnotetext{
${ }^{7}$ Jochim (1998) is an extremely valuable examination of Zhuang-Zi's conception of the self. Jochim argues that Zhuang $\mathrm{Zi}$ is not claiming that the self is non-existent, but merely that we ought not to concern ourselves with "having an excessive sense of being different from others, a feeling of being better than others, and an inability to go along with others" $(1998,53)$.

${ }^{8}$ Not the historical Confucius or Yen Hui but fictionalized versions created by Zhuang Zi to express ideas very unlike those of the real Confucius.
} 
Interestingly, emptiness does not imply that one becomes inactive but that one becomes more responsive to one's continually changing situation. Here is Confucius in response to Yen Hui:

You may go and play in his bird cage, but never be moved by fame. If he listens, then sing; if not, keep still. Have no gate, no opening, but make oneness your house and live with what cannot be avoided. Then you will be close to success. (Watson, Ch. 4)

There is much in these passages, which are some of the most famous in the Zhuang$Z i$, and the ideas of emptiness and responsive action are vital to Zhuang Zi's understanding of the education of the emotions. The ideas are reinforced near the end of the Inner Chapters (I use the Hinton translation, as it seems clearer than Watson's here):

Don't be a carcass of names

or treasure-house of schemes;

don't be a servant of pursuits

or proprietor of fine wisdom.

Make the inexhaustible your body

and wander beyond origins.

Make everything heaven gave you treasure enough

and know you have nothing.

Live empty, perfectly empty.

Sage masters always employ mind like a pure mirror;

welcome nothing, refuse nothing,

reflect everything, hold nothing.

And so they triumph over things with never a wound. (Hinton 1998, 112)

This is essential for Zhuang Zi's normative view of the emotions. It is difficult to analyze the mirror metaphor completely, but I take it to imply that our responses to the world are not to be too bound up with personal schemes, projects or attachments, that we ought to respond with little concern for our own identities and that we are to feel neither pride nor shame at our successes and failures. We must move toward Mou's (2008) "transcendental perspectivism."

It is clear that Zhuang $\mathrm{Zi}$ is not attempting to get us to have no emotions whatsoever. In Chapter 6 , in response to questioning from Huizi regarding whether one could be a "man" and really be without feelings, Zhuang Zi replies: "When I talk about feelings, I mean that a man doesn't allow likes or dislikes to get in and do him harm. He just lets things be the way they are and doesn't try to help life along." Zhuang $\mathrm{Zi}$ then chastises Hui $\mathrm{Zi}$, saying "you treat your spirit like an outsider" (Watson, Ch. 5). This latter comment is somewhat mysterious, but I read it as advising against emotions that arise from personal preferences and thereby cause harm to the subject (see Lenehan, 2013); other emotions are not rejected.

(c) Zhuang Zi's perspectivism and support for selflessness support his underlying ethic, which we can summarize with two interrelated concepts: wandering (yóu 遊) and natural spontaneity and natural action (wu-wei 無為). Wandering is one of the Zhuang-Zi's central metaphors, which supports being responsive to one's situation, 
being able to "go with the flow" of life, without inflexible binding attachments. The model is importantly non-rational in a crucial sense. The sage's responsiveness comes not from the mind (conceptual discrimination and "tallying things up"), but from "deeper" aspects of one's self. Overall, the principal normative picture is one of spontaneity, but it is clearly not a crude spontaneity. The picture is rather of a cultivated spontaneity that takes years to acquire. In Chapter 3 of the Zhuang-Zi there is the famous story of Cook Ding butchering an ox for Wen Hui, the King of Wei, with dance-like elegance:

Way is what I care about, and Way goes beyond mere skill. When I first began cutting up oxen, I could see nothing but the ox. After three years, I could see more than the ox. And now, I meet the ox in spirit. I've stopped looking with my eyes. When perception and understanding cease, the spirit moves freely. Trusting the principles of heaven, I send the blade slicing through huge crevices, lead it through huge hollows. Keeping my skill constant and essential, I just slip the blade through, never touching ligament or tendon, let alone bone. (Hinton 1998, 39-40)

The cook is clear that his skill is not entirely unconscious, as he notes that from time to time he meets with a difficult place, and must slow down and study the ox, "focus my vision, then work slowly, moving the blade with great delicacy" (Hinton 1998, 40). The careful slow deliberations of Ding in the challenging places makes it clear that $w u$-wei entails a balance between the opposites of spontaneity and nonspontaneity (Beng 2013). Perhaps this balance is why, whereas other cooks go through knives monthly, Ding has been using the same knife for nineteen years! Wen Hui is clearly impressed:

"How marvelous!" said King Wen Hui. "I listen to the words of a butcher, and suddenly I've learned how to care for life itself!" (Hinton 1998, 40)

Cook Ding exemplifies the natural, responsive spontaneity of the sage, inasmuch as he is not narrowly governed by intellectual principles that can be put into words in the form of clear rules or strategies. Fraser (2011) summarizes the sage's achievement of virtuosity:

He achieves a form of flexible, responsive agency that is self-sufficient or independent of contingent factors, in that it focuses on "wandering" through the world by flexibly adapting to and "riding along with things." (Fraser 2011, 102)

Fraser likens the sage's achievements with those of a seasoned athlete or other highly skilled agent:

Athletes, artistic performers, and craftspeople in various fields are all acquainted with the association between virtuoso performance and a loose, open, or 'empty' psychological state in which we unselfconsciously 'forget' ourselves, becoming more alert and responsive to our circumstances, remain calm and cool under pressure, and avoid misjudgment, hasty decisions, and faulty actions due to emotions or cognitive biases. (Fraser, 2011, 105-6)

\footnotetext{
${ }^{9}$ Fraser's (2011) text includes the Chinese characters for the relevant terms, but I have omitted them here.
} 
Slingerland (2014) argues that "it is becoming increasingly clear that the kind of cognitive flexibility that Zhuang Zi saw as so fatally lacking in his contemporaries is something that is best achieved when we weaken the hold of the conscious mind" $(2014,146)$.

This emphasis on letting go of the conscious mind in favor of responsive spontaneity is perhaps most at home in the Daoist tradition, where the idea of Dao is taken as real. If Dao is understood literally, then letting go of the conscious mind arguably allows one to let Dao take over. However, understood metaphorically, to counsel such letting go demands some further defense. The most promising tact is to suggest that the self is multilayered and that the conscious mind inhibits one's ability to be receptive to deeper layers. Think, for example, of how conscious planning gets in the way of alpine skiing or surfing, where it is best to be intuitively responsive to the hill or the wave. This point is explored very well in Fraser (2008)

It is tempting to gloss $w u$-wei as implying effortlessness, but this temptation ought to be resisted. The point is that the agent will experience action as natural, automatic and responsive, without too much self-consciousness or pre-meditated intentionality, but this is consistent with a great deal of effort in the action itself. Obviously, the athletes and artists alluded to in the above quote from Fraser (2011) will be expending great effort in their actions. That said, the actions will appear effortless, perhaps even to the athlete him or herself. Watch a great athlete-Serena Williams, Wayne Gretzky or Cristiano Ronaldo - and when they are "on" their actions seem to flow effortlessly, yet it is clear, from their sweat if nothing else, that their performances are anything but effortless.

Fraser (2011) argues that for Zhuang Zi the projects of wandering and natural spontaneity should be seen as higher-order values, formed in response to the variability of human life. The idea is that as we recognize the contingency of anything external to ourselves, we come to focus on what we can control, especially the project of wandering:

Our core values or commitments thus shift away from what we cannot control to what we can. We focus on the higher-order, ongoing process of wandering, rather than the outcome of any particular first-order activity. Having identified with this "constant," higher-order project, we experience affective equanimity, for we "bind" ourselves to no particular external things. (Fraser 2011, 108)

Looked at in this way, we remain able to participate in all manner of first-order projects, including sports, cookery, raising children or even a career in academic philosophy. However, one must remain unmoved by the outcomes of these projects, depending as they do on contingent matters.

This is one of the reasons why Zhuang $\mathrm{Zi}$ is uneasy about codified morality (see Beng 2013), as a set of rules that are intended to limit behavior. To the extent that we guide our lives by strict rules-don't lie, help the poor if you can, don't break promises-we are conscious of these rules, and this inhibits spontaneity. As Kupperman notes: "what Zhuangzi opposes seems to be an attitude toward morality - the conscious tailoring of behavior to moral norms - rather than behavior 
that in a natural way happens to comply with morality" (2001, 119). It is not, therefore, that Zhuang $\mathrm{Zi}$ rejects morality, but that he wants us not to focus on it consciously; such consciousness has the effect of distracting our focus. It is doubtful that Zhuang $\mathrm{Zi}$ would anticipate downright immoral behavior from sages, because the Dao no doubt would mitigate any unsocial behavior.

(d) I want to emphasize one other dimension of the Zhuang-Zi that is relevant for the education of the emotions-non-seriousness. Throughout the text there is a wonderful playfulness that is clearly part of its attraction. The fun that Zhuang $\mathrm{Zi}$ has with the character Confucius and representatives of the Mohist tradition are quite out of keeping with standard philosophy - instead they are bitingly sarcastic. Moreover, the attitude expressed regarding morality suggests that even with the weightiest dimensions of life, Zhuang $\mathrm{Zi}$ advises non-seriousness. Overall, I read the text as recommending a light bouyancy, allowing one to more easily go with the flow of the life.

I have identified four main themes in the Zhuang-Zi as particularly pertinent to its conception of a well-lived emotional life. The first thesis is a version of epistemological perspectivism. Second, Zhuang Zi supports decentering the self, at least in the sense that too much focus on the conscious self is a deterrent to effective action. Rather, we must learn to respond to the world more un-self-centeredly, alike in success or failure. Third, there are the interrelated ethics of natural spontaneity and wandering. We should live without preset principles or hardened standards, flexibly and naturally responding to whatever we cannot change. Fourth, there is the general support of non-seriousness in life. These four theses are implicit throughout the text, and present what I take to be a viable ethic. I turn now to applying these themes to the problem of the education of the emotions.

\section{ZHUANG ZI AND THE EDUCATION OF THE EMOTIONS}

As I noted at the outset, there are two components to any viable theory of educating the emotions: a normative account of what emotional life ought to be and a pedagogical account of how to get there. The normative vision, which could be referred to as "emotional intelligence," includes achievements such as awareness of one's own emotions, recognizing emotions in others, self-control and management of one's emotions, and managing the emotions of others in relationships (Goleman $1995)^{10}$. These domains obviously need more fleshing out, and this is where we can draw on Zhuang Zi. To illustrate how Zhuang Zi might help us with respect to fleshing out our normative vision for emotional life, it will be instructive to consider an alternative picture of a worthwhile emotional life.

Solomon (1983) argues that the goal of self-esteem underlies our fundamental projects:

\footnotetext{
${ }^{10}$ Part of the problem, as noted by Rietti (2008), is that none of the writers in emotional intelligence "really address the issue of justifying these particular values against possible criticisms and competitors, taking the goodness of self-actualization, independence, and respect for value-pluralism, largely as read (p. 639)
} 
We are fundamentally concerned with our Self-esteem, our regard for our Selves, our sense of Self-worth, the various ways in which we have invested our Selves in our world. It is the goal of Self-esteem that motivates our actions, our inquiries, and-most importantly_our passions. Self-esteem is the ultimate goal of every passion. (1983, 95-

6)

Zhuang Zi would be in widespread agreement with this as a descriptor of the lives of most people, but unlike Solomon, Zhuang Zi diagnoses this focus on self-esteem as the deep cause of our emotional challenges. Solomon, conceiving of emotions as a species of judgments, wants us to learn to make more rational judgments that will have the effect of supporting our long-term self-esteem. We can learn to have better emotions on his account because emotions have a cognitive core that is at some level open to rational judgment. Making these judgments more rationally, to achieve the goal of self-esteem, is the normative vision.

Against the sort of ideal expressed in Solomon, Zhuang Zi's ideal is of a life more or less free of self-serving emotions. The sage avoids self-centered or vain investment in her actions, but instead is sensitive and alert to her situation. Her performances focus on the exercise of her skill and her responsiveness to the tasks at hand, as Cook Ding butchering the ox. She concentrates on what she can control, recognizing that her efficacy ranges only so far and that there is much that is entirely out of her hands. When life puts new challenges in her way, she slows down and modifies her actions to suit the new reality, perhaps changing course entirely. Her emptiness is not a vice but an enabling and liberating virtue. Her emotional life is smooth, partly because she is not so self-centered, not so focused on the self-esteem that Solomon argues is central to human life. Furthermore, it is smooth also because she accepts the role of fate, and "lives with what cannot be avoided" (Watson, Ch. 4), and is thus at peace with her situation.

One of the greatest insights of Zhuang $\mathrm{Zi}$ is recognition of the uncontrollable in human life and its proposal on how to respond to it. ${ }^{11}$ Rather than focusing the education of the emotions on learning to have more rational emotions that better support self-esteem, Zhuang $\mathrm{Zi}$ wants us to focus on becoming less self-involved. It is not so much that emotions will thereby disappear from our lives, but rather that the emotions we experience will not be so focused on the self and its attachments to people or things. Such emotions as anger, fear, shame, embarrassment, sadness, jealousy, hatred, contempt, along with love and joy, are all primarily focused on the self and its attachments. We feel these emotions as we perceive the world or other people as affecting us. My fear implies the cognition of impending danger to myself or what I hold dear; my love is towards other people with whom I have an ongoing attachment; my shame is toward awareness of my inadequacy in some domain or the other. Indeed, these emotions reflect our fundamental attitudes or values.

The emotions that we ought to experience will be softer and less focused on the self. Think for example of the joyful appreciation of one's friend or lover. This joy

\footnotetext{
${ }^{11}$ There are interesting implications regarding the current focus on autonomy as an educational ideal if we take Zhuang Zi's position seriously, but these must be pursued elsewhere.
} 
need not reflect a demand to control the friend, to bend her wishes to one's own, but may merely be a gracious enjoyment of the time one has together. Another example might be the awe one can experience through art or perhaps nature, for example what one might feel on driving to a secluded spot on the mountains of the island of Hawai'i, where the stars appear dizzyingly vivid and near. A further example might be the quiet comfort experienced in contemplation. In addition to the calm nature of these emotions, they have in common that there is no clear sense of a desire to control the world. Instead, they represent an acceptance of the world; the sage would thereby eschew intense emotions.

This of course is the central issue on which the Zhuang-Zi depends regarding the emotions: to lack intense emotions is to lack intense values, and it is at least a legitimate challenge to show whether such a life could be worth living. It is common, if not natural, to see the intensity of one's emotions as an indication of one's values. The intensity of my worry over my daughter's well-being is one sign of how much I care for her; to lack emotion were she at risk would be seen as indicative of the importance I place upon her and my relationship with her. A life without any intense emotions would thereby be seen as a life without intense values, and it is difficult to know whether such a life is meaningful.

In defense of Zhuang Zi's view, however, we could respond that intense emotions often get in the way of good relationships. To care for another person does not demand intense emotions but rather kind acts that serve her well-being. Intense emotions often get in the way of kindness, focusing on oneself rather than the needs of the other person. Indeed, just as intense emotions - whether positive or negativeget in the way of effective skiing, playing billiards or cutting meat, they get in the way of caring relationships with other people. In caring one needs to focus on the other, and emotions distract from that focus.

This point is taken up in the Zhuang-Zi, although not in the "Inner Chapters." In Chapter 18, Zhuang Zi grieves after his wife's death ("like everyone else") until he sees her death as part of a natural process, likening her death to the passing of the seasons. He recovers from his grief, but there is no suggestion that he does not value her: "If I were to follow after her bawling and sobbing, it would show that I don't understand anything about her" (Watson, Ch. 18).

What of Zhuang Zi's strategies for attaining this sage-like form of life? How are we to learn to live like Zhuang Zi? What pedagogical strategies will be helpful? There are four interrelated points that I will briefly make on this issue.

First, Zhuang Zi repeatedly emphasizes the importance of diminishing focus on the self in our thoughts and actions. Most clearly, this is represented in the advice to practice "fasting of the mind," which demands making $Q i$ (氣) open by limiting from the mental activity of conceptualizing and making distinctions - practices that arise from the desire to fashion the world to our own perceived needs. It is clear that we cannot experience the world without some conceptualization, but we must learn to experience the world with minimal categorization, to accept the world without the need to fashion it to suit our particular projects. This makes possible a peaceful harmonization with our world (Kupperman 2001, 128). 
Second, one must learn playfulness as a fundamental orientation in the world. Seriousness regarding moral or rational principles inhibits responding openly and fully to the world. Schools or other institutions where all activities must present definite and explicit preconceived learning outcome is very much at odds with the lighthearted liveliness that is so attractive in the Zhuang-Zi. The demands for accountability, reflective practice and explicit pre-set learning outcomes might be justified, but they can be carried so far that schooling - and even parenting - can become unimaginative and plodding. The Zhuang-Zi serves us well in reminding us that our engagement with the world need not always be highly principled.

Third, we need to reflect the perspectivism in the Zhuang-Zi. The cognitive dimension of emotions implies that one way of changing our emotional experiences is by changing how we perceive our situations. However, Zhuang Zi suggests that there is more than one way to look at a situation, some which might never occur to us. One might be jealous of a colleague for his speedy progression through the ranks, but the jealousy might dissipate if one thinks of his poor personal relationships or of other aspects of life that he had to neglect in order to succeed. Zhuang Zi's perspectivism reminds us that there is usually another way to look at one's situation. This alone should mitigate the intensity of our emotions. Furthermore, Mou's (2008) transcendental perspectivism suggests that there will be a higher perspective that incorporates the other lower levels.

Finally, and perhaps most importantly, we must embrace the ethic of wandering and spontaneity in our lives. We must learn $w u$-wei $i^{12}$, which will entail adopting a life that expresses no hard commitments to particular goals or inflexible attachments to people or things, that recognizes the great part of life that cannot be managed by the individual, and that flexibly adapts to the contingencies that our lives encounter. The well-lived emotional life will be calm, but beautiful and elegant, like the (seemingly) effortless virtuosity of Lang Lang. Of course, this is far more easily said than done! Still, the first three points about pedagogy noted above will move us in the right direction.

\section{ACKNOWLEDGMENTS}

This paper has benefitted from discussions with my students, especially Xinyu Xi and Sarah Chan. The University of the Fraser Valley Library, especially Patti Wilson and Paula Brennan, went beyond the call of duty in assisting me in tracking down articles and getting my iPad to access some online materials. Most importantly, an earlier

\footnotetext{
12 Slingerland (2014) emphasizes that there is a paradox of "trying not to try" that plagues the development of $w u$-wei, not only in the Zhuang-Zi, but also throughout the Chinese philosophical tradition. The paradox he identifies has close affinities to the paradox of hedonism (see Sidgwick (1962) or Mill (2013). The paradox of wu-wei is that the achievement of effortless action seems to demand effort. See also R. S. Peters' discussion of the paradox of moral education (Peters, 1966a). Kazepides $(1979 ; 2010)$ argues that the paradox is only "apparent;" it is not a serious challenge to moral education.
} 
draft was subject to rigorous reviews by two anonymous referees from Comparative Philosophy; I cannot thank them enough for their careful and learned examination of my earlier work.

\section{REFERENCES}

Beng, P. G. C. (2013), "Spontaneity and Nonspontaneity in $W u-W e i$ as an Ethical Concept of Early Daoism," Philosophia: International Journal of Philosophy 14.1: $1-15$.

Chung, J. (2017), "Taking Skepticism Seriously: How the Zhuang-Zi Can Inform Contemporary Epistemology." Comparative Philosophy 8.2: 3-29.

Coutino, S. (2014), "Zhuangzi (Chuang-Tzu, 369-298 B.C.E.)", Internet Encyclopedia of Philosophy. $<\mathrm{http}: / /$ www.iep.utm.edu/Zhuang-Zi/>

Fraser, C. (2008), "Wu-Wei, the Background, and Intentionality", in Mou, B. (ed.) (2008), Searle's Philosophy and Chinese Philosophy: Constructive Engagement (Brill).

Fraser, C. (2011), "Emotion and Agency in Zhuangzi", Asian Philosophy 21.1: 97121.

Goleman, D. (1995), Emotional Intelligence: Why It Can Matter More than IQ (Bantam Books).

Hinton, D. (1998), Chuang Tzu: The Inner Chapters. Berkeley, CA: Counterpoint.

Jochim, C. (1998), “Just say No to 'No Self' in Zhuangzi”, in Ames, R. (ed.) Wandering at Ease in the Zhuangzi (Albany, NY: State University of New York Press).

Kazepides, T. (1979), "The Alleged Paradox of Moral Education," in Cochrane, D. B., Hamm, C.M., and Kazepides, A.C., The Domain of Moral Education (New York: Paulist Press).

Kazepides, T. (2010), Education as Dialogue: Its Prerequisites and its Enemies (Montreal and Kingston: McGill-Queens University Press).

Kirkland, R. (2004), Taoism: The Enduring Tradition (New York: Routledge: New York).

Kupperman, J. (2001), Classic Asian philosophy (Oxford: Oxford University Press).

Lenehan, K. (2013), "Theory of Non-Emotion in the Zhuangzi and its Connection to Wei-Jin Poetry", Journal of Chinese Philosophy 40.2: 340-354.

Levinovitz, A. (2012), "The Zhuangzi and You: Defining an Ideal Without Contradiction", Dao 11: 479-496.

Mill, J. S. (2013), Autobiography (E-book version) (Book Jungle).

Morgan, J. (1994), "Learning to Live with Emotion," Educational Philosophy and Theory 26.2: 67-81.

Morgan, J. (2015), "Emptiness and the Education of the Emotions", Educational Philosophy and Theory 47.3: 291-304. 
Mou, B. (2008), "Searle, Zhuang Zi, and Transcendental Perspectivism," in Mou, B. (ed.), Searle's Philosophy and Chinese Philosophy: Constructive Engagement (Brill).

Peters, R. S. (1966a), "Reason and Habit: The Paradox of Moral Education", in Scheffler, I., Philosophy and education (2nd ed.)(Boston: Allyn and Bacon, Inc.)

Peters, R. S. (1966b), Ethics and Education (London: George Allen and Unwin).

Peters, R. S. (1972). "The Education of the Emotions," in Dearden, R. F., Hirst, P.H., and Peters, R.S. (eds.), Education and the Development of Reason (London: Routledge and Kegan Paul).

Raphals, L. (1996), "Skeptical Strategies in the Zhuangzi and the Theaetetus," in Kjellberg, P. and Ivanhoe, P. J. (eds.), Essays on Skepticism, Relativism and Ethics in the Zhuangzi (Albany, NY: State University of New York Press).

Rietti, S. (2008), "Emotional intelligence as an Educational Goal: A Case for Caution", Journal of the Philosophy of Education 42.3-4: 631-643.

Searle, J. (2008), "Reply to Bo Mou," in Mou, B. (ed.), Searle's Philosophy and Chinese Philosophy: Constructive Engagement (Brill).

Sidgwick, H. (1962), The Methods of Ethics (Chicago: University of Chicago Press).

Slingerland, E. (2014), Trying Not to Try: The Art and Science of Spontaneity (New York: Crown Publishers).

Solomon, R. (1983), The Passions (Notre Dame, Indiana: University of Notre Dame Press).

Stocker, M. (1983), "Psychic Feelings", Australasian Journal of Philosophy 61.1: 526.

Watson, B. (2003), Zhuangzi: Basic Writings (E-book version) (New York: Columbia University Press).

Ziporyn, B. (2009), Zhuangzi: The Essential Writings, With Selections from Traditional Commentaries, translated, with Introduction and Notes by B. Ziporyn (Indianapolis: Hackett Publishing). 